\title{
Correction to: Screening of postpartum diabetes in women with gestational diabetes: high-risk subgroups and areas for improvements - the STRONG observational study
}

\author{
Angela Napoli ${ }^{1,2}$ - Laura Sciacca ${ }^{1,3} \cdot$ Basilio Pintaudi $^{1,4}$. Andrea Tumminia ${ }^{1,3}$. Maria Grazia Dalfrà ${ }^{5}$. Camilla Festa ${ }^{1}$. \\ Gloria Formoso $^{1,6} \cdot$ Raffaella Fresa $^{1,7}$. Giusi Graziano ${ }^{8}$. Cristina Lencioni $^{1,9}$. Antonio Nicolucci ${ }^{8}$. Maria Chiara Rossi ${ }^{8}$. \\ Elena Succurro ${ }^{1,10}$ - Maria Angela Sculli ${ }^{1,11}$ - Marina Scavini ${ }^{1,12}$ - Ester Vitacolonna ${ }^{1,13}$ - Matteo Bonomo ${ }^{1,4}$. \\ Elisabetta Torlone ${ }^{1,14}$ on behalf of the STRONG Study Collaborators and the AMD-SID Diabetes and Pregnancy \\ Study Group
}

Published online: 11 June 2021

(c) The Author(s) 2021

\section{Correction to: Acta Diabetologica} https://doi.org/10.1007/s00592-021-01707-9

Authors would like to correct the error in their publication.

Figure 3 contains a part in Italian language which is now removed.

The collaborator author names were tagged only in the author group but missed to process in Acknowledgements section. The collaborator author names now updated as Study group in the Acknowledgements section.

The original article has been corrected.

The original article can be found online at https://doi.org/10.1007/ s00592-021-01707-9.

Angela Napoli

angela.napoli@uniroma1.it

1 AMD-SID Diabetes and Pregnancy Study Group, Rome, Italy

2 Department of Clinical and Molecular Medicine, Sant'Andrea Hospital, Faculty of Medicine and Psychology, Sapienza University, Rome, Italy

3 Department of Clinical and Experimental Medicine, Endocrinology Section, University of Catania Medical School, Catania, Italy

4 SSD Diabetology, Ca' Granda Niguarda Hospital, Milan, Italy

5 Department of Medicine, University of Padova, Padova, Italy

6 Department of Medicine and Aging Sciences; Center for Advanced Studies and Technology (CAST, Ex CeSI-Met), G. D'Annunzio University, Chieti, Italy

7 Endocrinology and Diabetes Unit, ASL Salerno, Salerno, Italy
Open Access This article is licensed under a Creative Commons Attribution 4.0 International License, which permits use, sharing, adaptation, distribution and reproduction in any medium or format, as long as you give appropriate credit to the original author(s) and the source, provide a link to the Creative Commons licence, and indicate if changes were made. The images or other third party material in this article are included in the article's Creative Commons licence, unless indicated otherwise in a credit line to the material. If material is not included in the article's Creative Commons licence and your intended use is not permitted by statutory regulation or exceeds the permitted use, you will need to obtain permission directly from the copyright holder. To view a copy of this licence, visit http://creativecommons.org/licenses/by/4.0/.

Publisher's Note Springer Nature remains neutral with regard to jurisdictional claims in published maps and institutional affiliations.

8 CORESEARCH - Center for Outcomes Research and Clinical Epidemiology, Pescara, Italy

9 Diabetes and Endocrinology Unit, Usl Nord Ovest Tuscany, Lucca, Italy

10 Department of Medical and Surgical Sciences, University Magna Graecia of Catanzaro, Catanzaro, Italy

11 Endocrinology and Diabetes, Bianchi Melacrino Morelli Hospital, Reggio Calabria, Italy

12 Division of Immunology, Transplantation and Infectious Diseases, Diabetes Research Institute (DRI), IRCCS San Raffaele Scientific Institute, Milan, Italy

13 Department of Medicine and Aging, School of Medicine and Health Sciences, "G. D'Annunzio" University, Chieti-Pescara, Chieti, Italy

14 Internal Medicine, Endocrinology and Metabolism, S. Maria Della Misericordia Hospital, Perugia, Italy 